\title{
Synthesis and Characterization of Palladium Supported Amino Functionalized Magnetic-MOF-MIL-101 as an Efficient and Recoverable Catalyst for Mizoroki-Heck Cross-Coupling
}

\author{
Ayat Nuri ${ }^{1,2} \cdot$ Nemanja Vucetic $^{2} \cdot$ Jan-Henrik Smått ${ }^{3} \cdot$ Yaghoub Mansoori $^{1} \cdot$ Jyri-Pekka Mikkola $^{2,4} \cdot$ Dmitry Yu. Murzin $^{2}$
}

Received: 18 November 2019 / Accepted: 16 February 2020 / Published online: 2 March 2020

(c) The Author(s) 2020

\section{Abstract}

Magnetic particles were prepared by a hydrothermal method and then successively covered by Metal-Organic-Frameworks MIL-101- $\mathrm{NH}_{2}$ with a high surface area. This was followed by deposition of $\mathrm{Pd}(\mathrm{OAc})_{2}$ on $\mathrm{Fe}_{3} \mathrm{O}_{4}-\mathrm{NH}_{2} @ \mathrm{MIL}^{-101-\mathrm{NH}_{2}}$ particles. The final catalyst was characterized with FT-IR, nitrogen physisorption, thermogravimetry (TGA), scanning electron microscopy (SEM) combined with energy dispersive X-ray analysis (EDX), transmission electron microscopy (TEM), vibrating sample magnetometry (VSM), wide-angle X-ray diffraction spectroscopy (XRD) and X-ray photoelectron spectroscopy (XPS). The prepared magnetic catalyst was effectively used in the Heck coupling reaction in the presence of an inorganic base. The reaction parameters such as the base type, amounts of catalyst and solvents, temperature, and substrates ratios were optimized. The catalyst was then magnetically separated, washed, and reused 7 times without losing significantly catalytic activity.

\section{Graphic Abstract}

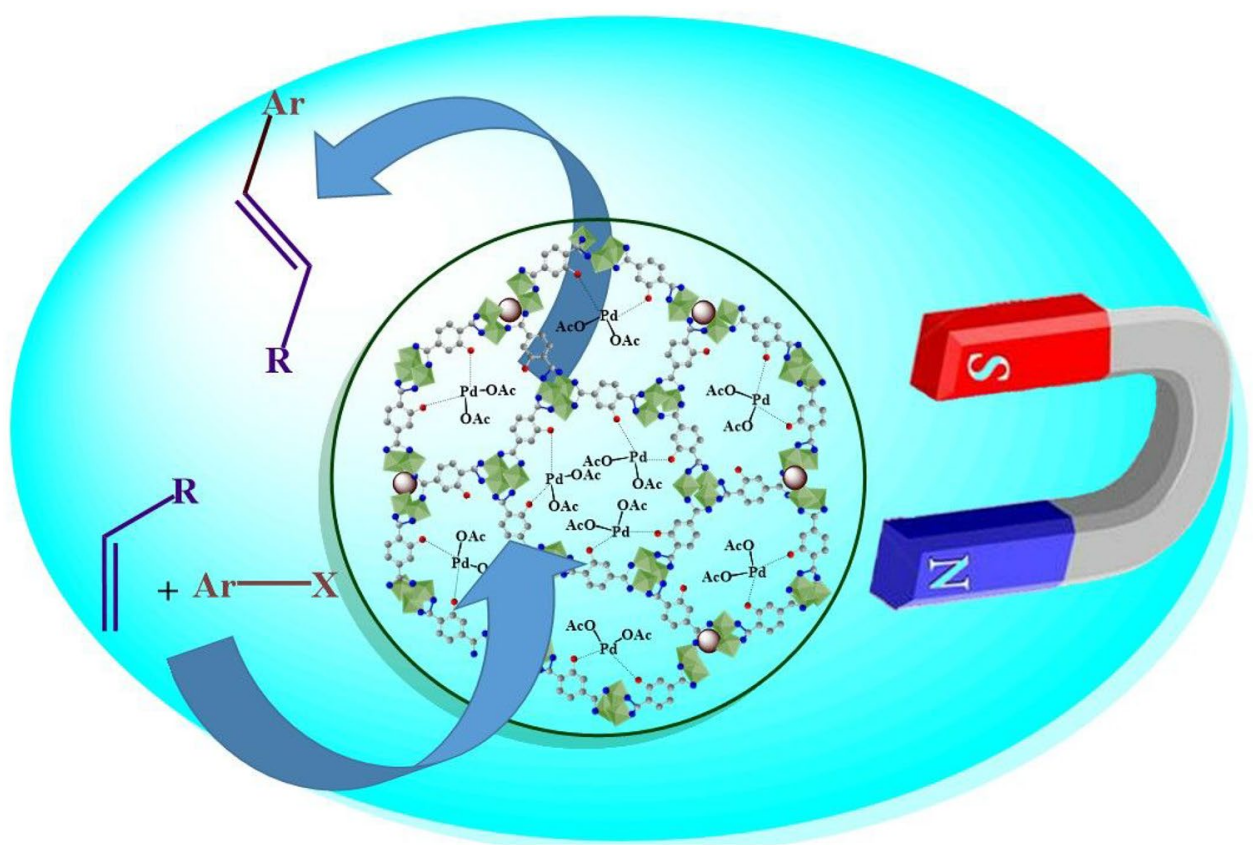

Keywords Metal-organic-frameworks $\cdot \mathrm{Fe}_{3} \mathrm{O}_{4}-\mathrm{NH}_{2} @ \mathrm{MIL}-101-\mathrm{NH}_{2} \cdot$ Magnetic nanoparticles $\cdot$ Heck reaction

Extended author information available on the last page of the article 


\section{Introduction}

An important method in organic synthesis is the reaction of aryl and vinyl halides with olefins catalyzed by palladium such the Mizoroki-Heck cross-coupling reaction [1-3] giving two types of products, namely $\mathrm{E}$ and Z. Generally, this reaction is carried out with high (E)-selectivity (Scheme 1) [4].

Cross-coupling reactions is a powerful way for creating $\mathrm{C}-\mathrm{C}$ single bonds and generating molecular diversity which causes highly selective linkage of $\mathrm{R}$ to $\mathrm{R}^{\prime}$ molecules while avoiding the formation of $\mathrm{R}-\mathrm{R}$ or $\mathrm{R}^{\prime}-\mathrm{R}^{\prime}$. This reaction has different variants and can be done both intra-molecularly and inter-molecularly. The latter has been extensively reported in the literature along the years [5], while the former version of the Heck reaction was reported much more recently [6]. A variety of reagents such as bromo and chloro derivatives with unactivated alkenes were utilized for synthesizing Heck products, the most industrially relevant studies were conducted with aryl bromides [7]. In most cases, the coupling reactions occur in the presence of palladium as a catalyst [8]. Other metals are also used to catalyze the Heck reaction, for example, nickel having many advantages being abundant, non-toxic, and cost effective [9].

Recovery of noble metals is very important in terms of costs and environmental impact and it is one of the main issues in homogeneous catalysts [10]. On the other hand, easier recycling of heterogeneous catalysts is an important advantage, while clear disadvantages of heterogeneous catalysts are related to insufficient selectivity and catalyst leaching [11].

In order to achieve an easy separation and recycling heterogeneous Pd catalysts have been developed [12]. For example, de Vries et al. [13] reported enantioselective reductive Heck reaction with supported palladium. Zhang et al. [14] prepared an active and magnetically separable silica-coated nano- $\mathrm{Fe}_{3} \mathrm{O}_{4}$-supported iminopyridine palladium complex for the Heck reaction. Khajehzadeh et al. synthesized a new NHC-Pd complex immobilized on nanosilica as a reusable highly efficient heterogeneous catalyst for the Heck-Mizoroki $\mathrm{C}-\mathrm{C}$ coupling reaction [15].

Other supports have also attracted attention recently. Among them are metal-organic frameworks (MOFs) i.e. porous materials with metal building units connected by

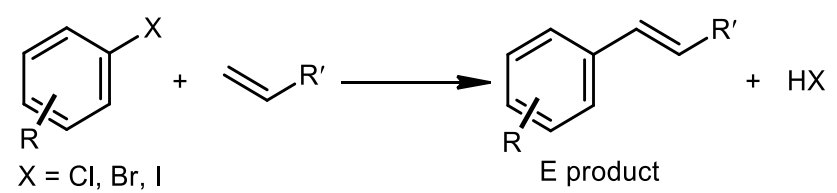

Scheme 1 Scheme of Heck reaction organic groups [16]. Their advantages are related to tunable compositions, high porosity and readiness of functionalization with organic ligands for some chemical and physical processing. These compounds can be applied across various areas such as clean energy, gas storage media for such gases as hydrogen and methane, drug delivery, catalysis, separation and chemical sensing [16, 17]. More than $90 \%$ volume of the crystalline MOF material is porosity, thereby surface areas of these materials are very high (close to $6000 \mathrm{~m}^{2} / \mathrm{g}$ ) [16]. One of the excellent MOF materials with thermal (up to $300{ }^{\circ} \mathrm{C}$ ) and chemical stability to water and common organic solvents, as well as a high specific surface area and pore volume is MIL-101(Cr). This MOF contains mesoporous cages (2.9 and $3.4 \mathrm{~nm}$ ) and microporous windows (1.2 and $1.6 \mathrm{~nm})$. Wang and co-workers fabricated amine-functionalized MIL-101(Cr) with $2.74 \mathrm{~nm}$ pore size and studied its catalytic activity in oxidative desulfurization under mild conditions [18]. Amine functionality had a purpose to stabilize a catalytically active anion through electrostatic interactions thus enabling catalyst reusability.

Recently, MOFs started to be widely used as heterogeneous catalysts, especially those encapsulated with metals nanoparticles such as $\mathrm{Pt}, \mathrm{Pd}, \mathrm{Ru}$ and $\mathrm{Au}$ [19]. For example, MIL-101 modified with Pd nanoparticles exhibited excellent catalytic performance in tandem dehydrogenation and can selectively reduce the nitro compounds to the corresponding amines with quantitative yields [20]. Tunable MOF-based catalysts were prepared through rational linker engineering, followed by palladium nanoparticles incorporation in m-6,6'-Me ${ }_{2}$ bpy-MOF and testing for Suzuki-Miyaura crosscoupling reactions [21]. This modified MOF exhibited a considerable enhancement in activity in comparison with the non-functionalized m-bpy-MOF-Pd and m-4,4'-Me 2 bpyMOF-Pd because the functionalized linker affects the catalytic activity with stereoelectronic properties. An inspiring approach was provided by Huang et al., who encapsulated Pd into amine-functionalized framework and used it for dehalogantion of aryl chlorides [22], while Pascanu et al. successfully applied the same concept for a cross-coupling reaction [23]. Due to affinity of palladium to coordinate with nitrogen this catalyst displayed a great stability, with reusability of more than ten times in the case of the Suzuki-Miyaura reaction.

Another interesting direction is to apply magnetic nanoparticles due to the possibility of their magnetic separation. Magnetic materials have been intensively investigated, for example, in stimuli-responsive cancer imaging [24], drug delivery [25], extraction [26] and heterogeneous catalysis [27]. For instance, Gholinejad and co-workers used supported palladium on magnetic nanoparticles modified with carbon quantum dots to catalyze the Suzuki reaction [28]. Recyclable magnetic $\mathrm{Fe}_{3} \mathrm{O}_{4}-\mathrm{TiO}_{2}$-L-dopa modified with 
$\mathrm{Cu}(0)$ was applied as a catalyst for the Chan-Lam crosscoupling reaction [29].

Combination of magnetic nanoparticles and MOF provides advantages of both high surface area and magnetic properties [30, 31]. Tang et al. reported excellent activity of magnetic metal-organic framework MIL-101 composites to directly catalyze luminol chemiluminescence without extra oxidants [32].

The present work is focused on synthesis and characterization of a magnetic amino-functionalized MOF-MIL101-Pd complex as an efficient and reusable catalyst for the Mizoroki-Heck cross-coupling.

\section{Experimental}

\subsection{Materials}

1, 6-hexanediamine, $\mathrm{FeCl}_{3} \cdot 6 \mathrm{H}_{2} \mathrm{O}$, anhydrous sodium acetate, 2-aminoterephthalic acid, $\mathrm{Pd}(\mathrm{OAc})_{2}, \mathrm{Cr}\left(\mathrm{NO}_{3}\right)_{3} \cdot 9 \mathrm{H}_{2} \mathrm{O}$, iodobenzene, ethyl acrylate and bases were obtained from Sigma Aldrich and used without further purification. Other solvents and chemicals were of laboratory grade, obtained from Alfa and used without further purification.

\subsection{Synthesis of $\mathrm{Fe}_{3} \mathrm{O}_{4}$ Nanoparticles Functionalized with Amine Groups}

In order to synthesize amine-functionalized magnetic particles $\left(\mathrm{Fe}_{3} \mathrm{O}_{4}\right)$ an approach reported in the literature was followed [33]. A mixture of 1, 6-hexanediamine (5 ml, $36.15 \mathrm{mmol}), \mathrm{FeCl}_{3} \cdot 6 \mathrm{H}_{2} \mathrm{O}(1.0 \mathrm{~g}, 3.7 \mathrm{mmol})$, glycol $(30 \mathrm{ml})$, and anhydrous sodium acetate $(2.0 \mathrm{~g}, 24.4 \mathrm{mmol})$ was introduced into the round bottom $50 \mathrm{ml}$ reaction flask and then stirred vigorously at $50{ }^{\circ} \mathrm{C}$. After $30 \mathrm{~min}$ the transparent solution was transferred into a Teflon-lined autoclave and kept at $190{ }^{\circ} \mathrm{C}$ for $6 \mathrm{~h}$. Thereafter, the magnetic particles were separated with an external magnetic field (magnet) and washed with water and ethanol to remove unreacted materials and then dried at $50{ }^{\circ} \mathrm{C}$.

\subsection{Synthesis $\mathrm{Fe}_{3} \mathrm{O}_{4}-\mathrm{NH}_{2} @ M I L-101-\mathrm{NH}_{2}$ Composites}

2-aminoterephthalic acid $(2.5 \mathrm{mmol})$ and $\mathrm{Cr}\left(\mathrm{NO}_{3}\right)_{3} \cdot 9 \mathrm{H}_{2} \mathrm{O}$ $(2.5 \mathrm{mmol})$ were dissolved in distilled water $(10 \mathrm{ml})$ and stirred for $30 \mathrm{~min}$. Magnetic $\mathrm{Fe}_{3} \mathrm{O}_{4}-\mathrm{NH}_{2}$ particles $(0.10 \mathrm{~g})$ after ultra-sonication for $10 \mathrm{~min}$ in distillate water $(5 \mathrm{ml})$ were added under stirring into the above mentioned mixture. The mixture was vigorously stirred for 20 min until it became uniform and then sealed in a stainless steel Teflonlined autoclave $200 \mathrm{ml}$. The reaction mixture in the autoclave was heated at $218{ }^{\circ} \mathrm{C}$ for $18 \mathrm{~h}$. After the reaction, the magnetic MOF MIL-101- $\mathrm{NH}_{2}$ material was separated by an external magnetic field (magnet). The magnetic composites were washed with warm $\left(100{ }^{\circ} \mathrm{C}\right)$ distilled water for $5 \mathrm{~h}$, ethanol $\left(60{ }^{\circ} \mathrm{C}\right)$ for $3 \mathrm{~h}$, and then were dried overnight in vacuum at $120{ }^{\circ} \mathrm{C}$ following the literature procedure [33].

\subsection{Preparation of $\mathrm{Fe}_{3} \mathrm{O}_{4}-\mathrm{NH}_{2} @ \mathrm{MIL}-101-\mathrm{NH}_{2} /$ $\operatorname{Pd}(\mathrm{OAc})_{2}$}

The activated MNP@MIL-101-NH 2 particles (500 mg) were first dispersed in $\mathrm{CH}_{2} \mathrm{Cl}_{2}(30 \mathrm{~mL})$ with ultrasound, followed by addition of $\mathrm{Pd}(\mathrm{OAc})_{2}(22 \mathrm{mg})$ and stirring of the mixture for $24 \mathrm{~h}$. Thereafter the solid magnetic catalyst was separated with an external magnetic field (magnet) washed several times with $\mathrm{CH}_{2} \mathrm{Cl}_{2}$ and dried under vacuum at $150{ }^{\circ} \mathrm{C}$ for $24 \mathrm{~h}$ giving $\mathrm{Fe}_{3} \mathrm{O}_{4}-\mathrm{NH}_{2} @ \mathrm{MIL}-101-\mathrm{NH}_{2} / \mathrm{Pd}(\mathrm{OAc})_{2}$ with $1.74 \mathrm{wt} \% \mathrm{Pd}$. The synthesis protocol was previously reported in the literature [12].

\subsection{Characterization}

The functional groups on the solid compounds were investigated by infrared spectroscopy (ATI Mattson FTIR). The specific surface area and pore volume were determined by $\mathrm{N}_{2}$ adsorption/desorption using a Sorptometer 1900 apparatus (Carlo-Erba Instruments). The morphology and crystal size distribution of magnetic nanoparticles, magnetic MOF and Pd supported on the magnetic MOF were studied by a scanning electron microscope (Zeiss Leo 1530 Gemini) equipped with a Thermo-NORAN vantage $X$-ray detector. Elemental analysis was performed with the same instrument. The magnetic nanoparticles and magnetic composite size distributions images were obtained by transmission electron microscopy (TEM), carried out on EFTEM, LEO 912 OMEGA, LaB6 filament, $120 \mathrm{kV}$. TGA curves were recorded on a CHAN D-200 instrument for the powder samples (scanning rate $10{ }^{\circ} \mathrm{C} / \mathrm{min}$ to $600^{\circ} \mathrm{C}$ ). The content of palladium in the catalyst was determined by inductively coupled plasma optical emission spectroscopy (ICP-OES), using an Optima 4300 DV optical atomic emission spectrometer. X-ray photoelectron spectroscopy (XPS) data of the as prepared sample were obtained with an Kratos Axis Ultra DLD electron spectrometer from monochromated $\mathrm{Al} \mathrm{K}$ source operated at $150 \mathrm{~W}$. The binding energy (BE) scale was referenced to the $\mathrm{Si} 2 \mathrm{p}$ line set at $103.3 \mathrm{eV}$. The XRD measurements were carried out on a Bruker AXS D8 Discover instrument equipped with a $\mathrm{Cu} \mathrm{K}_{\alpha} \mathrm{X}$-ray source and scintillator point detector. The samples were scanned in the $1^{\circ}-70^{\circ} 2 \theta$ range, with an increment of $0.04^{\circ}$ and at a scan speed of $8 \mathrm{~s}$ per point. Analysis of the reaction products was carried out with a gas chromatograph with Agilent $19091 \mathrm{~J}-113$ HP-5, 5\% phenyl methyl siloxane column $(30 \mathrm{~m}, 320 \mu \mathrm{m}, 0.50 \mu \mathrm{m})$ and the gas flow of $9.5 \mathrm{ml} / \mathrm{min}$. The injector and detector temperature were at $280{ }^{\circ} \mathrm{C}$. 


\subsection{Heck Coupling}

The Heck reaction was performed by using $1.0 \mathrm{mmol}$ of iodobenzene, $3.0 \mathrm{mmol}$ methyl acrylate, $1.5 \mathrm{mmol} \mathrm{Cs}_{2} \mathrm{CO}_{3}$, $0.005 \mathrm{~g} \mathrm{Fe}_{3} \mathrm{O}_{4}-\mathrm{NH}_{2} @$ MIL-101- $\mathrm{NH}_{2} / \mathrm{Pd}(\mathrm{OAc})_{2}$ as a catalyst (0.082 mol\% Pd to aryl halide) and $1.0 \mathrm{ml}$ DMAc (dimethylacetamide) as a solvent at $120{ }^{\circ} \mathrm{C}$ for $30 \mathrm{~min}$. The reaction was carried in a round bottom glass vial with Teflon screw $(14 \mathrm{ml})$ heated by an oil bath. The reaction progress was monitored by TLC and after completion analyzed with GC. The catalyst was separated from the reaction mixture with an external magnetic field (magnet) and the reaction mixture was washed with diethyl ether and ethyl acetate. The organic phase was separated after evaporation of the solvent under reduced pressure. The pure products were obtained by plate chromatography on silica.

\section{Results and Discussion}

\subsection{Catalyst Synthesis and Characterization}

Magnetite nanoparticles were prepared by the co-precipitation method and then coordinated by Metal-OrganicFramework MIL-101- $\mathrm{NH}_{2}$. The as prepared nanoparticles were then used as a support to deposit Pd. The mixture of magnetic nanoparticles, 2-aminoterephetalic acid and
$\mathrm{Cr}\left(\mathrm{NO}_{3}\right)_{3} \cdot 9 \mathrm{H}_{2} \mathrm{O}$ was vigorously stirred and dispersed uniformly into a round bottom reaction flask, then transferred to Teflon-lined autoclave and kept at $218^{\circ} \mathrm{C}$ for $18 \mathrm{~h}$. After separation, the magnetic MOF were washed and reacted with $\mathrm{Pd}(\mathrm{OAc})_{2}$ (Scheme 2).

In the FT-IR spectra characteristic bands revealed the presence of functional groups in $\mathrm{Fe}_{3} \mathrm{O}_{4}-\mathrm{NH}_{2} @ \mathrm{MIL}-$ $101-\mathrm{NH}_{2}$ and $\mathrm{Fe}_{3} \mathrm{O}_{4}-\mathrm{NH}_{2} @ \mathrm{MIL}-101-\mathrm{NH}_{2}-\mathrm{Pd}(\mathrm{OAc})_{2}$ as shown in Fig. 1. The strong peak of magnetite is visible at $589 \mathrm{~cm}^{-1}$ [34], while a sharp peak at ca. $510 \mathrm{~cm}^{-1}$ to $580 \mathrm{~cm}^{-1}$ can be assigned to $\mathrm{Cr}-\mathrm{O}$ bonding [35]. The $\mathrm{N}-\mathrm{H}$ stretching (scissoring) vibration is present at $1617 \mathrm{~cm}^{-1}$ [36], while the strong bands at $1576,1545 \mathrm{~cm}^{-1}$ and $1406 \mathrm{~cm}^{-1}$ are related to symmetrical and unsymmetrical $\mathrm{O}-\mathrm{C}=\mathrm{O}$ vibrations of dicarboxylate and aromatic structure, respectively [37]. The strong peak at $1199 \mathrm{~cm}^{-1}$ is related to $\mathrm{C}-\mathrm{N}$ stretching. The aromatic $\mathrm{C}-\mathrm{H}$ bending at 1064 and $811 \mathrm{~cm}^{-1}$ also appeared in the spectra of magnetic MIL-101 [37]. The peak at $770 \mathrm{~cm}^{-1}$ can be assigned to the stretching $\mathrm{N}-\mathrm{H}$ vibrations [38].

The magnetization curves were obtained using VibratingSample Magnetometer (VSM) at room temperature over a range of applied fields between 5000 and -5000 Oe. The saturation magnetization values $\left(\mathrm{M}_{\mathrm{s}}\right)$ of the prepared nanocomposite are in the range of $24.70-71.80 \mathrm{emu} \mathrm{g}^{-1}$. The saturation magnetization value of $\mathrm{Fe}_{3} \mathrm{O}_{4}-\mathrm{NH}_{2}$ was found to be $71.80 \mathrm{emu} \mathrm{g}^{-1}$, which decreased to 25.9 and $24.7 \mathrm{emu}$

Scheme 2 Synthesis of supported $\mathrm{Fe}_{3} \mathrm{O}_{4}-\mathrm{NH}_{2} @ \mathrm{MOF}-$ MIL-101- $\mathrm{NH}_{2}-\mathrm{Pd}$ complex

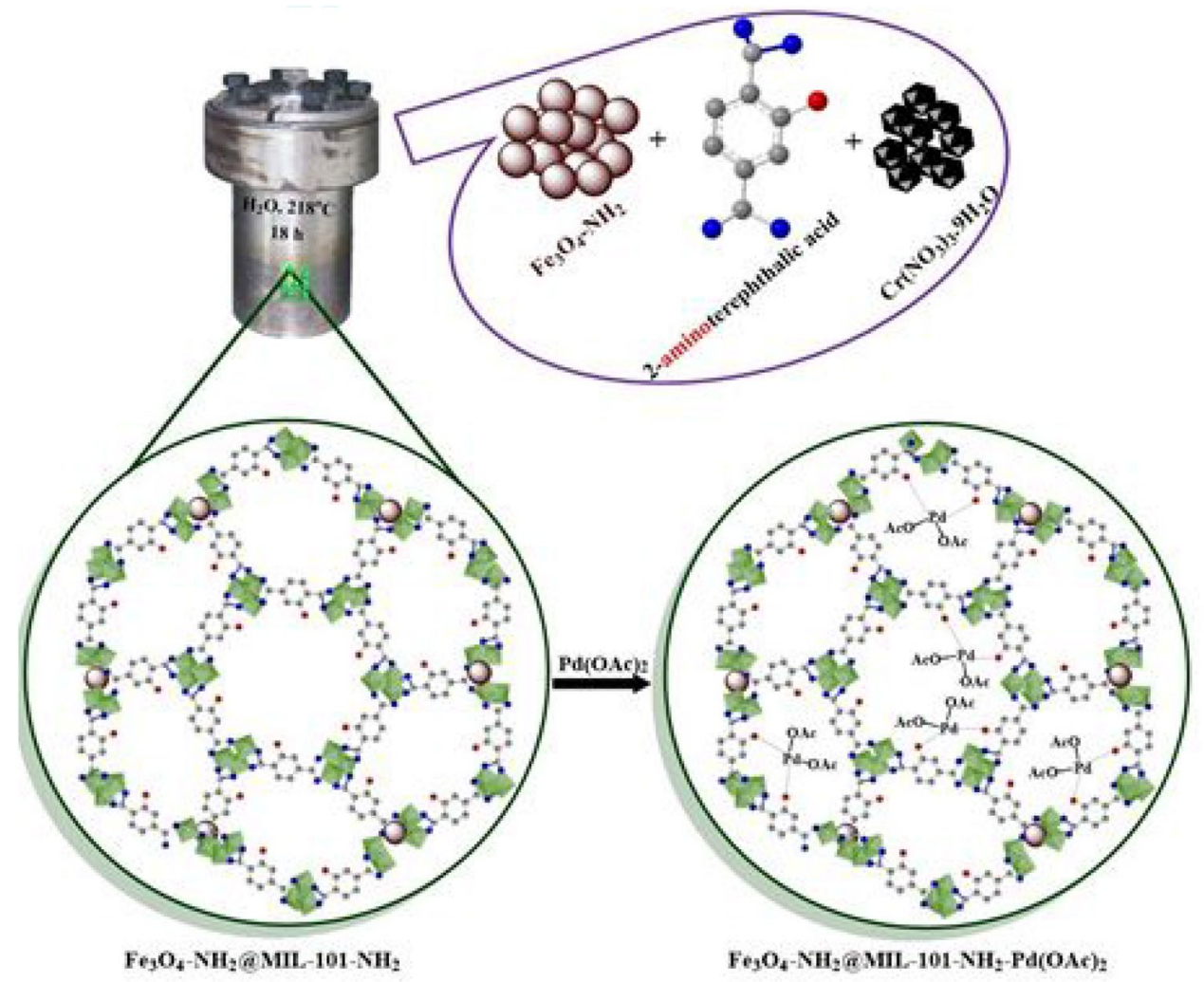


Fig. 1 FT-IR spectra for $\mathrm{Fe}_{3} \mathrm{O}_{4}-$ $\mathrm{NH}_{2}$ (black line), $\mathrm{Fe}_{3} \mathrm{O}_{4}-\mathrm{NH}_{2} @$ MIL-101- $\mathrm{NH}_{2}$ (red line) and $\mathrm{Pd}(\mathrm{OAc})_{2}$ supported on $\mathrm{Fe}_{3} \mathrm{O}_{4}-$ $\mathrm{NH}_{2} @ \mathrm{MIL}-101-\mathrm{NH}_{2}$ (green line)

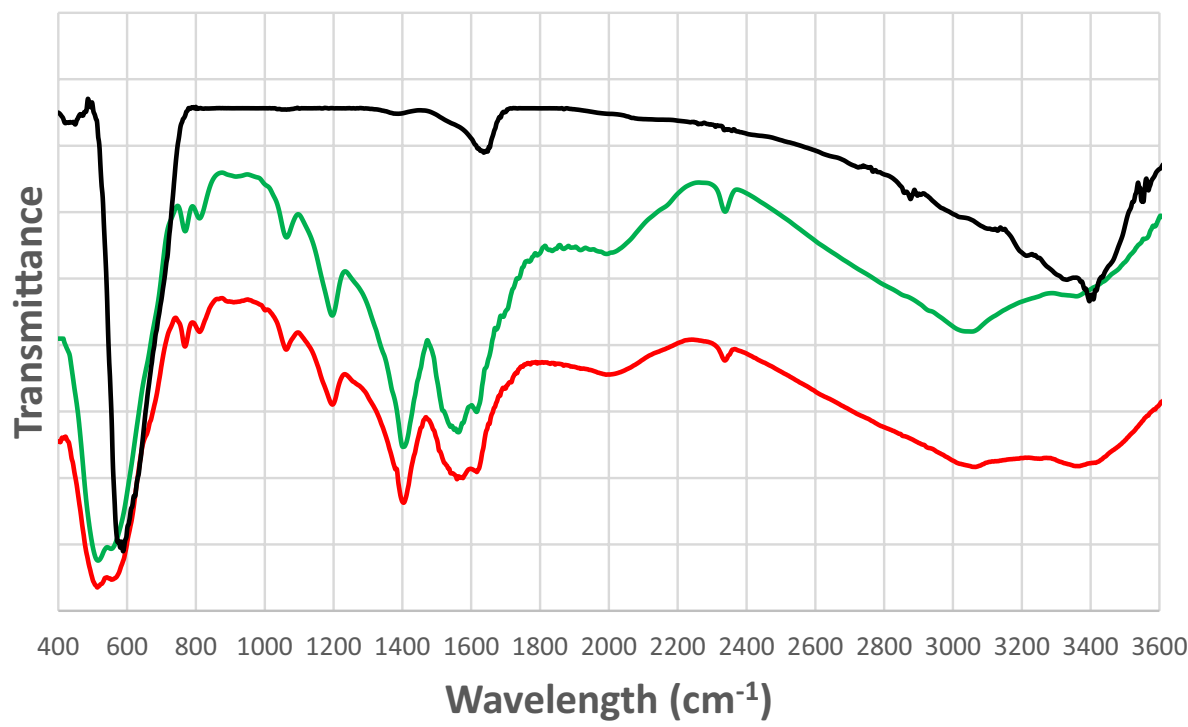

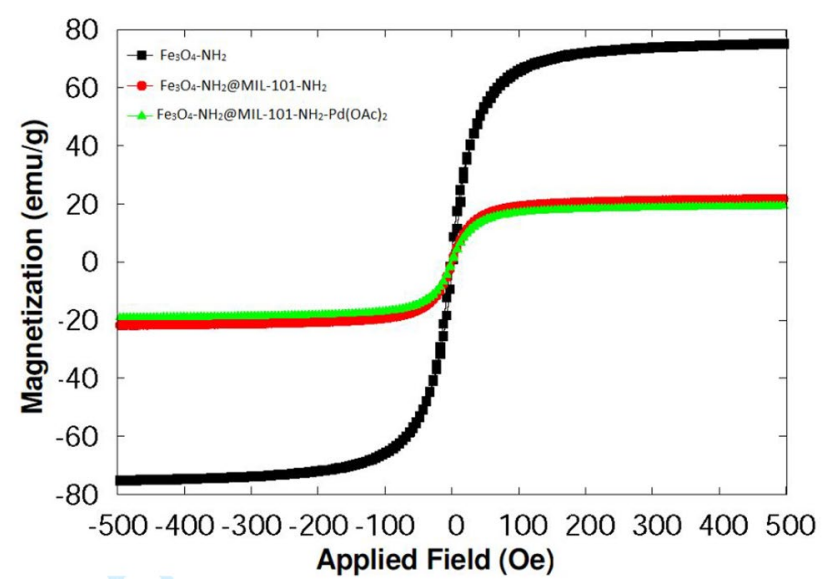

Fig. 2 Hysteresis loops of $\mathrm{Fe}_{3} \mathrm{O}_{4}-\mathrm{NH}_{2}, \mathrm{Fe}_{3} \mathrm{O}_{4}-\mathrm{NH}_{2} @ \mathrm{MIL}-101-\mathrm{NH}_{2}$ and $\mathrm{Fe}_{3} \mathrm{O}_{4}-\mathrm{NH}_{2} @ \mathrm{MIL}-101-\mathrm{NH}_{2}-\mathrm{Pd}(\mathrm{OAc})_{2}$

$\mathrm{g}^{-1}$ for $\mathrm{Fe}_{3} \mathrm{O}_{4}-\mathrm{NH}_{2} @ \mathrm{MIL}-101-\mathrm{NH}_{2}$ and $\mathrm{Fe}_{3} \mathrm{O}_{4}-\mathrm{NH}_{2} @ \mathrm{MIL}-$ $101-\mathrm{NH}_{2}-\mathrm{Pd}(\mathrm{OAc})_{2}$ respectively (Fig. 2), showing that the weight fraction of magnetic particles in the composites is about 36 and $34.4 \mathrm{wt} \%$. In comparison with the literature [33] the magnetization of magnetic nanoparticles in this work is high. Formation of MOF-MIL-101- $\mathrm{NH}_{2}$ and loading of palladium acetate is clearly responsible for decreasing the magnetization values. Nevertheless, the level of magnetization for $\mathrm{Fe}_{3} \mathrm{O}_{4}-\mathrm{NH}_{2} @ \mathrm{MIL}-101-\mathrm{NH}_{2}$ and $\mathrm{Fe}_{3} \mathrm{O}_{4}-\mathrm{NH}_{2} @$ MIL-101- $\mathrm{NH}_{2}-\mathrm{Pd}(\mathrm{OAc})_{2}$ is sufficient for easy separation with common external magnets. From the viewpoint of catalysis it is considered that iron does not possess any catalytic activity in the Heck reaction.

The structure of MIL-101- $\mathrm{NH}_{2}$, magnetic MIL$101-\mathrm{NH}_{2}-\mathrm{Pd}(\mathrm{OAc})_{2}$ nanocatalyst and magnetic nanoparticles was elucidated using powder X-ray diffraction (Fig. 3).
The characteristic pattern for MIL-101 is in the region below $2 \theta=20^{\circ}$ [39]. All X-ray diffraction peaks of magnetic nanoparticles are in agreement with the literature data for $\mathrm{Fe}_{3} \mathrm{O}_{4}$ (JCPD Scard No. 19-629) [40]. When MOF was introduced onto magnetic nanoparticles, the structure of MIL-101- $\mathrm{NH}_{2}$ was preserved albeit decreasing peaks intensity.

The nitrogen adsorption-desorption isotherm was analyzed with the Brunauer-Emmett-Teller (BET) method for calculating the area of $\mathrm{Fe}_{3} \mathrm{O}_{4}-\mathrm{NH}_{2} @ \mathrm{MIL}-101-\mathrm{NH}_{2}$ and $\mathrm{Fe}_{3} \mathrm{O}_{4}-\mathrm{NH}_{2} @ \mathrm{MIL}-101-\mathrm{NH}_{2}-\mathrm{Pd}(\mathrm{OAc})_{2}$. The BET surface area for $\mathrm{Fe}_{3} \mathrm{O}_{4}-\mathrm{NH}_{2} @$ MIL-101- $\mathrm{NH}_{2}$ was calculated to be $1300 \mathrm{~m}^{2} / \mathrm{g}$. After deposition of palladium acetate on $\mathrm{Fe}_{3} \mathrm{O}_{4} @$ MIL-101- $\mathrm{NH}_{2}$, the surface area was diminished to $970 \mathrm{~m}^{2} / \mathrm{g}$.

The thermogravimetric analysis (Fig. 4) shows the thermal stability of magnetic nanoparticles with and without MOF. The weight loss for magnetic nanoparticles per se of overall ca. $6 \mathrm{wt} \%$ is related to water desorbed from the surface (2 wt \%) while approximately $4 \mathrm{wt} \%$ losses are related to aliphatic organic compound on the surface of magnetite. The magnetic MOF MIL-101- $\mathrm{NH}_{2}$ exhibited two main weight losses, the first one (app. 7\%) in the temperature range below $250{ }^{\circ} \mathrm{C}$, corresponding to the loss of water from the pores of metal organic frameworks as well as aliphatic groups and unreacted molecules. A second more prominent mass loss of $23.5 \%$ around $250-300{ }^{\circ} \mathrm{C}$, was related to the decomposition of the organic frameworks which is in relatively good agreement with literature whereas MIL-101- $\mathrm{NH}_{2}$ exhibit thermal stability up to $300{ }^{\circ} \mathrm{C}[41]$.

The qualitative elemental composition of $\mathrm{Fe}_{3} \mathrm{O}_{4}-\mathrm{NH}_{2} @$ MIL-101- $\mathrm{NH}_{2}-\mathrm{Pd}(\mathrm{OAc})_{2}$ was evaluated by EDX at random points on the surface as presented in Fig. 5. The measurements confirmed the presence of iron, chromium, palladium, oxygen, nitrogen and carbon atoms in the supported catalyst. The weight $\%$ and atomic $\%$ of the 
Fig. 3 XRD patterns of (a) MIL-101- $\mathrm{NH}_{2}$, (b) $\mathrm{Fe}_{3} \mathrm{O}_{4}-$ $\mathrm{NH}_{2} @ \mathrm{MIL}-101-\mathrm{NH}_{2}-\mathrm{Pd}(\mathrm{OAc})_{2}$ and (c) $\mathrm{Fe}_{3} \mathrm{O}_{4}-\mathrm{NH}_{2}$

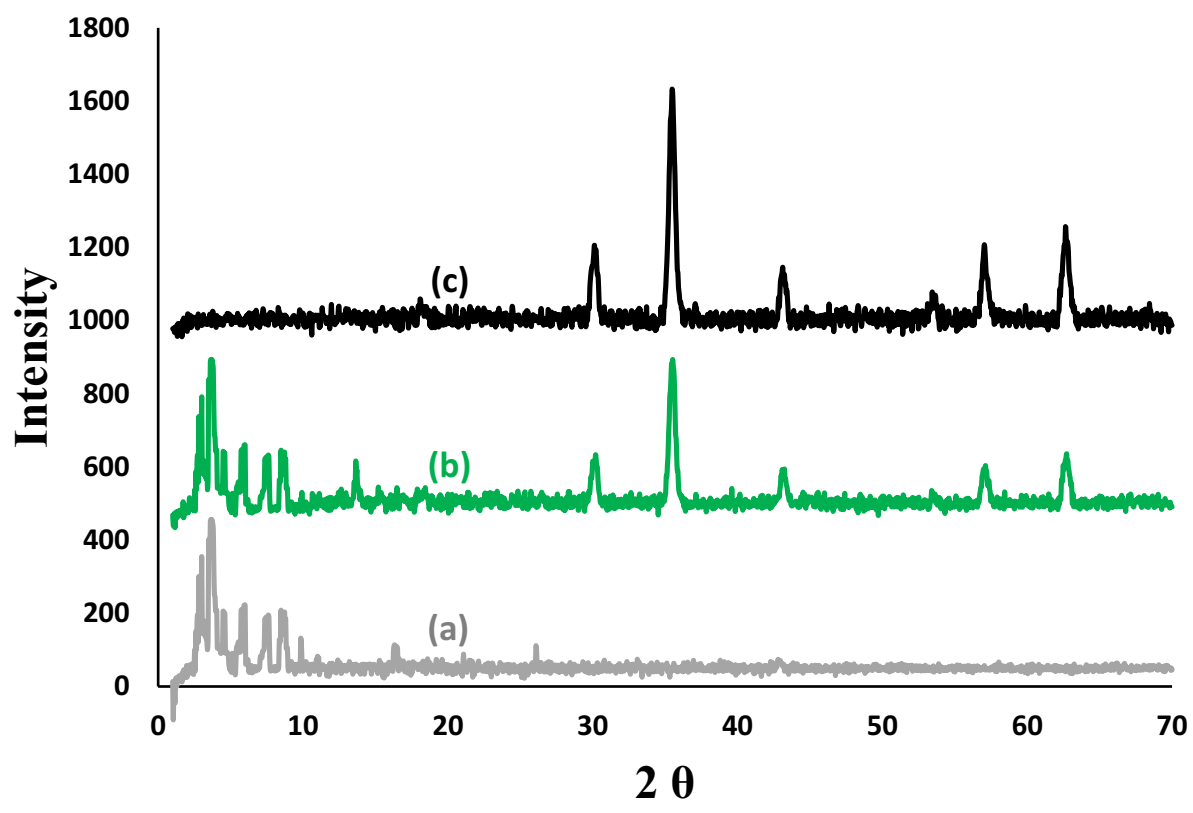

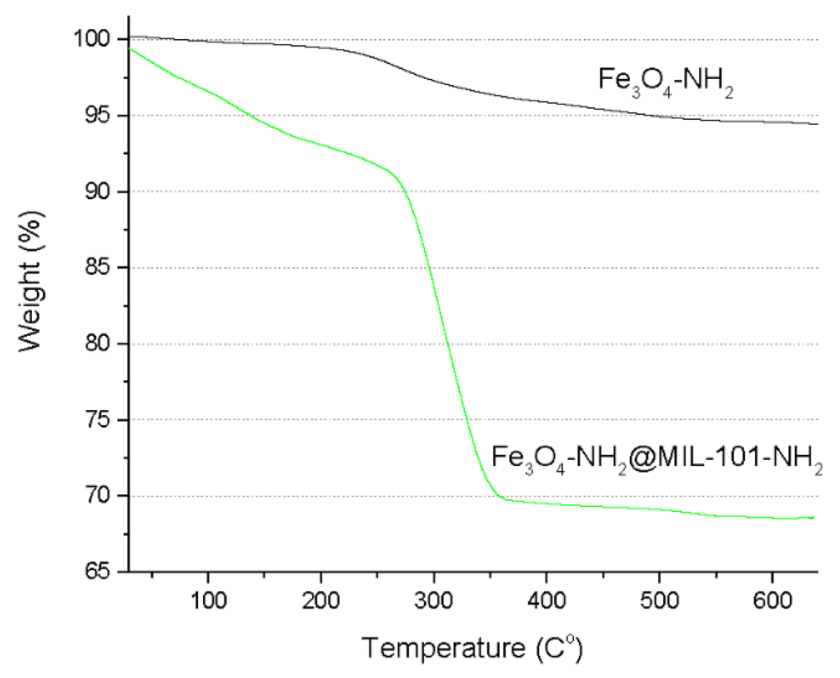

Fig. 4 TGA thermograms of magnetite and magnetic MOF MIL$101-\mathrm{NH}_{2}$ nanoparticles

elements in the catalyst are shown in Table 1, with a note that the value of a carbon amount was excluded from calculation since carbon tape was used as a support during the analysis.

The XPS spectra of the magnetic MIL-101- $\mathrm{NH}_{2}$ before and after deposition of Pd are shown in Fig. 6. XPS survey shows the synthesized nanocomposite containing five elements (iron, chromium, oxygen, nitrogen, carbon, and

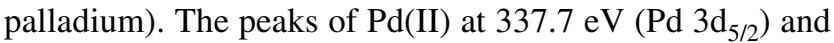

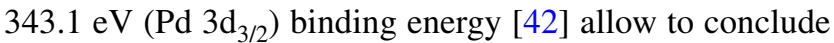
that palladium(II) on the surface of magnetic MOF particles is not reduced.
Figure 7 shows typical SEM images of the $\mathrm{Fe}_{3} \mathrm{O}_{4}-\mathrm{NH}_{2}$, $\mathrm{Fe}_{3} \mathrm{O}_{4}-\mathrm{NH}_{2} @ \mathrm{MIL}-101-\mathrm{NH}_{2}$ and $\mathrm{Fe}_{3} \mathrm{O}_{4}-\mathrm{NH}_{2} @$ MIL$101-\mathrm{NH}_{2}-\mathrm{Pd}(\mathrm{OAc})_{2}$. According to SEM images, the morphology of magnetic nanoparticles is spherical and uniform (Fig. 7a). After coating magnetic nanoparticles with MOF MIL-101- $\mathrm{NH}_{2}$ the spherical morphology of magnetic nanoparticles disappeared as visible from Fig. 7b, c illustrating also that magnetic particles are non-uniformly deposited on the surface of MIL-101.

Deeper insight was obtained with TEM analysis of $\mathrm{Fe}_{3} \mathrm{O}_{4}-\mathrm{NH}_{2}, \mathrm{Fe}_{3} \mathrm{O}_{4}-\mathrm{NH}_{2} @ \mathrm{MIL}-101-\mathrm{NH}_{2}$ and $\mathrm{Fe}_{3} \mathrm{O}_{4}-\mathrm{NH}_{2} @ \mathrm{MIL}-101-\mathrm{NH}_{2}-\mathrm{Pd}(\mathrm{OAc})_{2}$ materials (Fig. 8). The average particle size for $\mathrm{Fe}_{3} \mathrm{O}_{4}$ was calculated to be below $30 \mathrm{~nm}$. The size of obtained Fe nanoparticles indicate that they cannot fit into the small MOF cages, on the contrary, being coordinated with MOF yielding thus a nanocomposite kind of material. Comparing Fig. 8a that corresponds to synthesized Fe nanoparticles before introduction of MOF with the material after such introduction (Fig. 8b), a lack of individual iron nanoparticles (or their agglomerates) and presence of some coordinated structures is evident. The most important contribution to $\mathrm{Fe}-\mathrm{MOF}$ interactions was ascribed to basic amino functionalities of $\mathrm{Fe}_{3} \mathrm{O}_{4}-\mathrm{NH}_{2}$ which have a potential to bond unsaturated chromium sites in frameworks [33].

Palladium nanoparticles were not observed, which is in agreement with XPS indication that all palladium is in non-metallic form. On the other hand, it is questionable if it would be even possible to distinguish palladium from iron nanoparticles due to the limited resolution of the instrument. 
Fig. 5 EDX analysis of $\mathrm{Fe}_{3} \mathrm{O}_{4}-$ $\mathrm{NH}_{2} @ \mathrm{MIL}-101-\mathrm{NH}_{2}-\mathrm{Pd}(\mathrm{OAc})_{2}$

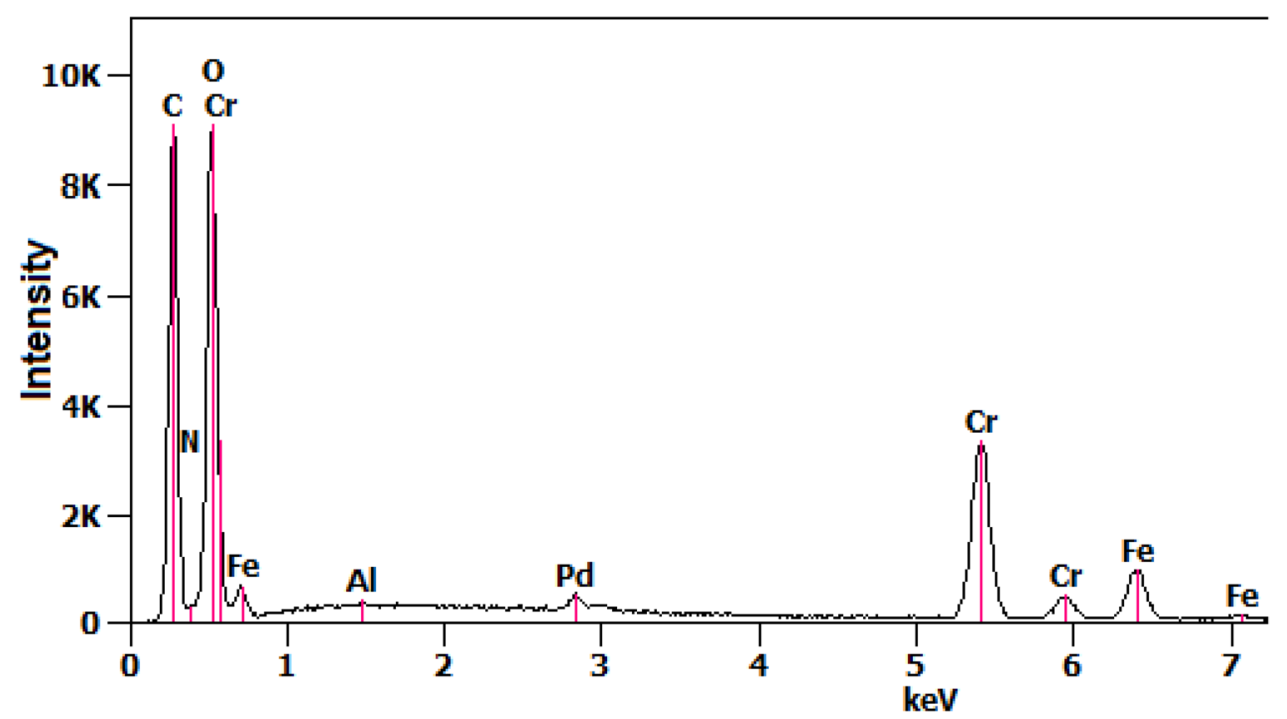

Table 1 The weight $\%$ and atomic $\%$ of $\mathrm{Fe}_{3} \mathrm{O}_{4}-\mathrm{NH}_{2} @$ MIL-101- $\mathrm{NH}_{2}-$ $\mathrm{Pd}(\mathrm{OAc})_{2}$

\begin{tabular}{lcc}
\hline Element & Wt. $(\%)$ & Atom $(\%)$ \\
\hline Nitrogen & 5.16 & 7.78 \\
Oxygen & 51.60 & 68.10 \\
Iron & 9.78 & 10.86 \\
Chromium & 29.29 & 11.89 \\
Palladium & 3.24 & 0.64 \\
\hline
\end{tabular}

\subsection{Optimization of Reaction Conditions}

The reaction conditions were optimized by conducting the coupling reaction of iodobenzene and methyl acrylate as a model reaction and changing the reaction parameters including the base type, solvent, catalyst amount, reactants molar ratio, amount of base and reaction temperature. The results are summarized in Table 2. From the very beginning, experiments were performed in DMF, since it is a common
Fig. 6 XPS spectra of magnetic MOF: (a) $\mathrm{Fe}_{3} \mathrm{O}_{4}-\mathrm{NH}_{2} @$ MIL$101-\mathrm{NH}_{2}$, (b) $\mathrm{Fe}_{3} \mathrm{O}_{4}-\mathrm{NH}_{2} @$ MIL-101- $\mathrm{NH}_{2}-\mathrm{Pd}(\mathrm{II})$

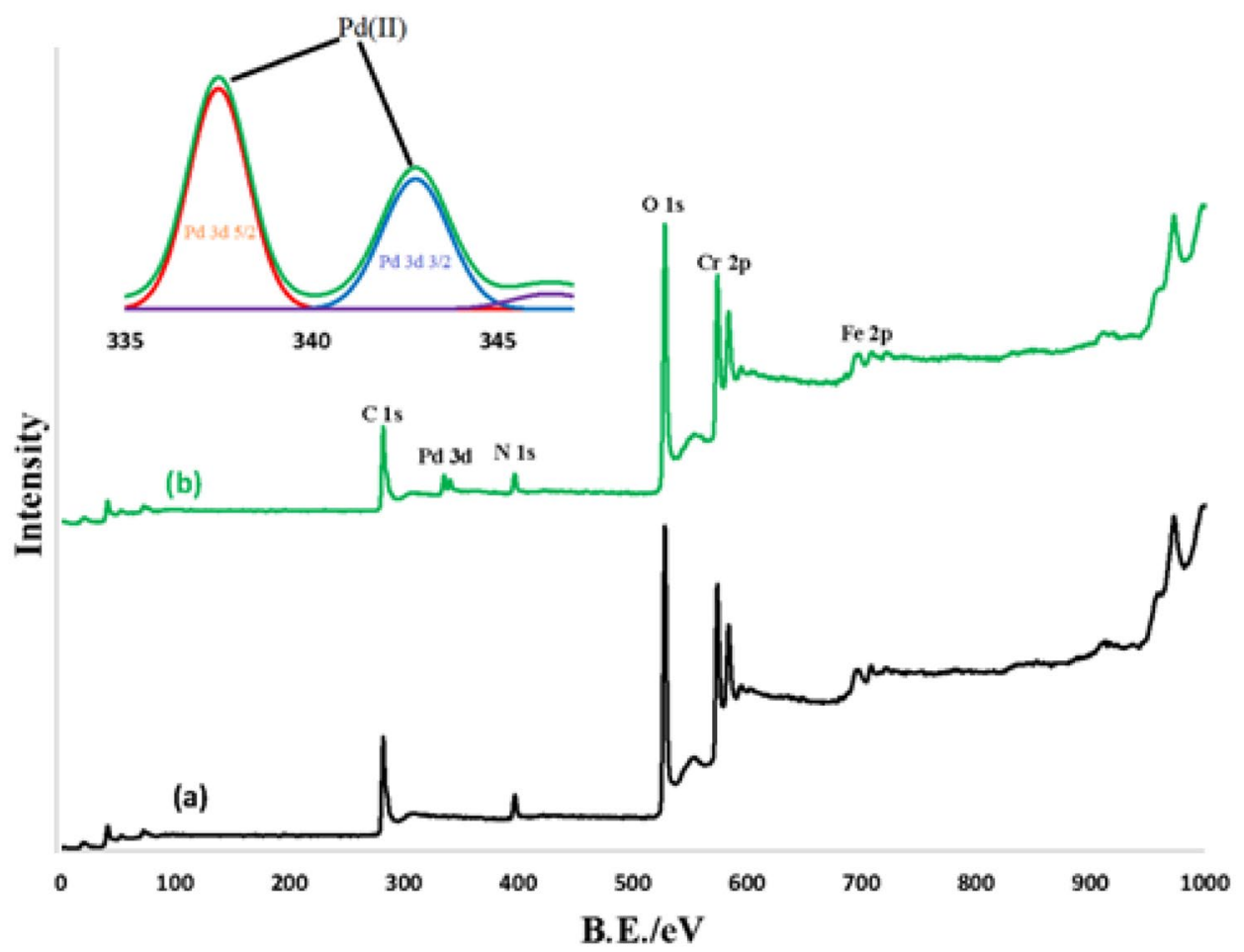



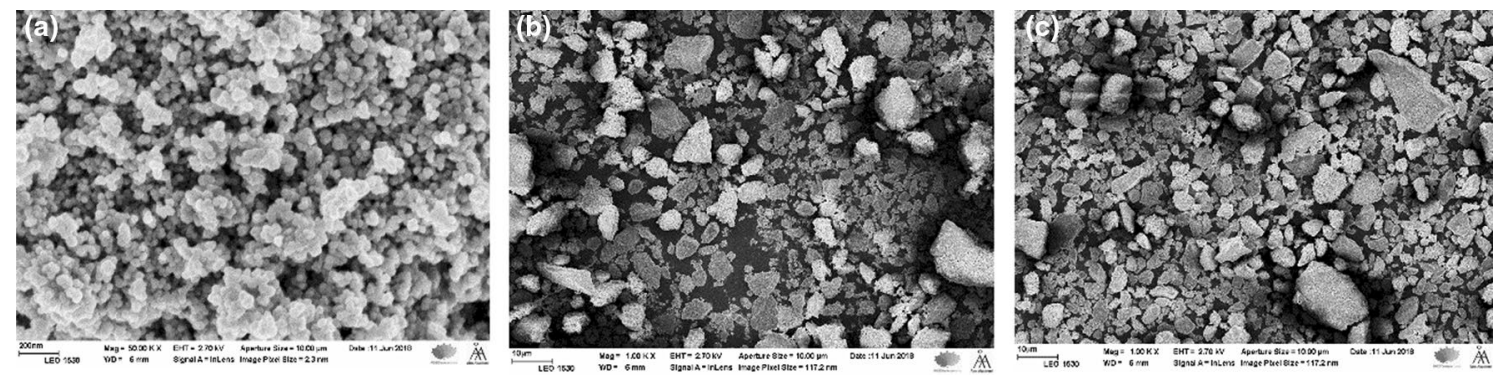

Fig. 7 SEM images of (a) $\mathrm{Fe}_{3} \mathrm{O}_{4}-\mathrm{NH}_{2}$ (b) $\mathrm{Fe}_{3} \mathrm{O}_{4}-\mathrm{NH}_{2} @ \mathrm{MIL}-101-\mathrm{NH}_{2}$ (c) $\mathrm{Fe}_{3} \mathrm{O}_{4}-\mathrm{NH}_{2} @$ MIL-101- $\mathrm{NH}_{2}-\mathrm{Pd}(\mathrm{OAc})_{2}$
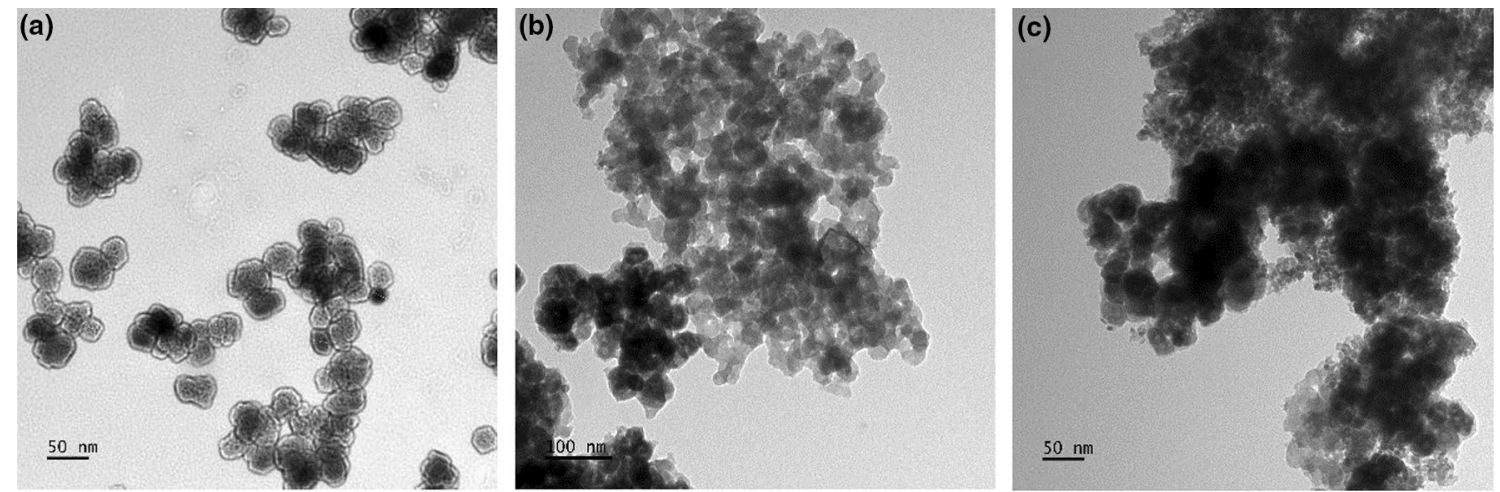

Fig. 8 TEM images of (a) $\mathrm{Fe}_{3} \mathrm{O}_{4}-\mathrm{NH}_{2}$ (b) $\mathrm{Fe}_{3} \mathrm{O}_{4}-\mathrm{NH}_{2} @ \mathrm{MIL}-101-\mathrm{NH}_{2}$ (c) $\mathrm{Fe}_{3} \mathrm{O}_{4}-\mathrm{NH}_{2} @ \mathrm{MIL}-101-\mathrm{Pd}(\mathrm{OAc})_{2}$

solvent for the Heck reaction. Methyl acrylate was added in excess to stoichiometry, because of a low boiling point and the possibility of its evaporation. After a careful screening of different bases (Entries 1 to 8), $\mathrm{Cs}_{2} \mathrm{CO}_{3}$ was found to give the highest yield of the coupling product (Entry 8, 96\% yield). This outcome is a result of the cesium cations softness, which also makes $\mathrm{Cs}_{2} \mathrm{CO}_{3}$ rather soluble in many organic solvents [43, 44]. Besides the Heck reactions [45, 46], cesium carbonate showed superiority also in Suzuki [47] and Sonogashira [48, 49] coupling reactions.

It is noteworthy that the conversion was very low in the absence of any base (Entry 7,10\% yield), while the major homocouple product (biphenyl) was observed in the presence of a strong base such as potassium tert-butoxide (Entry 2).

After optimization of the base, experiments with various solvents (Entry 8-19) revealed that dimethylacetamide (DMAc) was the most effective solvent (Entry 19, 99\% yield). The results of solvent optimization suggest that polar aprotic solvents with a high boiling point are better than other solvents. It is assumed that the polarity of the solvents has a strong influence on the solubilization and stabilization of palladium [50].

In the first set of experiments (Entry 1-19), the palladium amount of $0.82 \mathrm{~mol} \%$ was chosen along with the reaction time of $60 \mathrm{~min}$ to afford high yields, while it is generally known, that much smaller amounts of palladium can successfully lead the reaction to completion [51, 52]. Dependence of the catalyst behavior on the catalyst concentration can be seen from Entries 20-24. It was observed that almost complete conversion can be achieved by substantially decreasing the catalyst amount. These results are in line with those studies which suggest that the solid catalyst is just a pre-catalytic species in the Heck reaction, while the real catalyst is leached palladium which is redeposited back on the surface after complete iodobenzene consumption [53-55]. Finally, it appeared that even $0.082 \mathrm{~mol} \%$ of palladium-to-substrate loading (5 $\mathrm{mg}$ of catalyst) afforded a sufficient amount of active palladium to catalyze the reaction in one hour (Entry 24).

Further experiments with this catalyst loading and changing the molar ratio of ArX to acrylate gave the highest conversion at the 1:3 molar ratio (Entry 25-29). An over-stoichiometric amount of methyl acrylate is a consequence of its low boiling point $\left(80^{\circ} \mathrm{C}\right)$ meaning that under reaction conditions a certain amount of acrylate is evaporated. Based on the ideal gas low and the Clausius-Clapeyron equation it was calculated that at $100{ }^{\circ} \mathrm{C}$ approximately $0.8 \mathrm{mmol}$ of the total amount of methyl acrylate is present in the gas phase. 
Table 2 Optimization of conditions for the Heck reaction

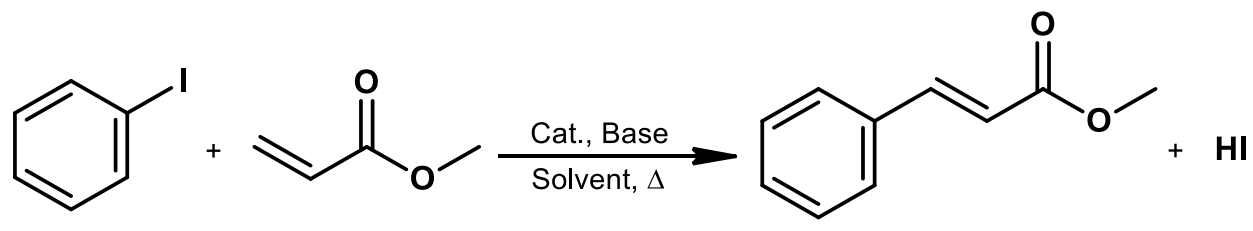

\begin{tabular}{|c|c|c|c|c|c|c|c|}
\hline Entry & Solvent & $\operatorname{Pd}(\mathrm{mol} \%)$ & Base/mmol & ArX:Acrylate & Temperature & Time (min) & Yield $(\%)^{\mathrm{c}}$ \\
\hline 1 & DMF & 0.82 & $\mathrm{~K}_{2} \mathrm{CO}_{3} / 1.5$ & $1: 2$ & 100 & 60 & 90 \\
\hline 2 & DMF & 0.82 & $\mathrm{KOtBu} / 1.5$ & $1: 2$ & 100 & 60 & 13 \\
\hline 3 & DMF & 0.82 & $\mathrm{HMT}^{\mathrm{a}} / 1.5$ & $1: 2$ & 100 & 60 & 90 \\
\hline 4 & DMF & 0.82 & $\mathrm{Et}_{3} \mathrm{~N} / 1.5$ & $1: 2$ & 100 & 60 & 92 \\
\hline 5 & DMF & 0.82 & DBU/1.5 & $1: 2$ & 100 & 60 & Trace \\
\hline 6 & DMF & 0.82 & $\mathrm{NaOAc} / 1.5$ & $1: 2$ & 100 & 60 & 40 \\
\hline 7 & DMF & 0.82 & Free & $1: 2$ & 100 & 60 & 10 \\
\hline 8 & DMF & 0.82 & $\mathrm{Cs}_{2} \mathrm{CO}_{3} / 1.5$ & $1: 2$ & 100 & 60 & 96 \\
\hline 9 & $\mathrm{H}_{2} \mathrm{O}$ & 0.82 & $\mathrm{Cs}_{2} \mathrm{CO}_{3} / 1.5$ & $1: 2$ & 100 & 60 & Trace \\
\hline 10 & NMP & 0.82 & $\mathrm{Cs}_{2} \mathrm{CO}_{3} / 1.5$ & $1: 2$ & 100 & 60 & 90 \\
\hline 11 & $\mathrm{H}_{2} \mathrm{O} / \mathrm{DMF}^{\mathrm{b}}$ & 0.82 & $\mathrm{Cs}_{2} \mathrm{CO}_{3} / 1.5$ & $1: 2$ & 100 & 60 & 30 \\
\hline 12 & DMSO & 0.82 & $\mathrm{Cs}_{2} \mathrm{CO}_{3} / 1.5$ & $1: 2$ & 100 & 60 & 85 \\
\hline 13 & Toluene & 0.82 & $\mathrm{Cs}_{2} \mathrm{CO}_{3} / 1.5$ & $1: 2$ & 100 & 60 & 45 \\
\hline 14 & Dioxane & 0.82 & $\mathrm{Cs}_{2} \mathrm{CO}_{3} / 1.5$ & $1: 2$ & 100 & 60 & 15 \\
\hline 15 & $\mathrm{CH}_{3} \mathrm{CN}$ & 0.82 & $\mathrm{Cs}_{2} \mathrm{CO}_{3} / 1.5$ & $1: 2$ & 82 & 60 & 35 \\
\hline 16 & $\mathrm{EtOH}$ & 0.82 & $\mathrm{Cs}_{2} \mathrm{CO}_{3} / 1.5$ & $1: 2$ & 78 & 60 & 20 \\
\hline 17 & Acetone & 0.82 & $\mathrm{Cs}_{2} \mathrm{CO}_{3} / 1.5$ & $1: 2$ & 56 & 60 & 30 \\
\hline 18 & $\mathrm{CH}_{2} \mathrm{Cl}_{2}$ & 0.82 & $\mathrm{Cs}_{2} \mathrm{CO}_{3} / 1.5$ & $1: 2$ & 39 & 60 & 10 \\
\hline 19 & DMAc & 0.82 & $\mathrm{Cs}_{2} \mathrm{CO}_{3} / 1.5$ & $1: 2$ & 100 & 60 & 99 \\
\hline 20 & DMAc & 0.410 & $\mathrm{Cs}_{2} \mathrm{CO}_{3} / 1.5$ & $1: 2$ & 100 & 30 & 99 \\
\hline 21 & DMAc & 0.328 & $\mathrm{Cs}_{2} \mathrm{CO}_{3} / 1.5$ & $1: 2$ & 100 & 35 & 99 \\
\hline 22 & DMAc & 0.246 & $\mathrm{Cs}_{2} \mathrm{CO}_{3} / 1.5$ & $1: 2$ & 100 & 40 & 99 \\
\hline 23 & DMAc & 0.164 & $\mathrm{Cs}_{2} \mathrm{CO}_{3} / 1.5$ & $1: 2$ & 100 & 50 & 99 \\
\hline 24 & DMAc & 0.082 & $\mathrm{Cs}_{2} \mathrm{CO}_{3} / 1.5$ & $1: 2$ & 100 & 60 & 99 \\
\hline 25 & DMAc & 0.082 & $\mathrm{Cs}_{2} \mathrm{CO}_{3} / 1.5$ & $1: 1$ & 100 & 40 & 90 \\
\hline 26 & DMAc & 0.082 & $\mathrm{Cs}_{2} \mathrm{CO}_{3} / 1.5$ & $1: 1.5$ & 100 & 40 & 90 \\
\hline 27 & DMAc & 0.082 & $\mathrm{Cs}_{2} \mathrm{CO}_{3} / 1.5$ & $1: 2$ & 100 & 40 & 92 \\
\hline 28 & DMAc & 0.082 & $\mathrm{Cs}_{2} \mathrm{CO}_{3} / 1.5$ & $1: 2.5$ & 100 & 40 & 95 \\
\hline 29 & DMAc & 0.082 & $\mathrm{Cs}_{2} \mathrm{CO}_{3} / 1.5$ & $1: 3$ & 100 & 40 & 99 \\
\hline 30 & DMAc & 0.082 & $\mathrm{Cs}_{2} \mathrm{CO}_{3} / 0.5$ & $1: 3$ & 100 & 60 & 70 \\
\hline 31 & DMAc & 0.082 & $\mathrm{Cs}_{2} \mathrm{CO}_{3} / 1$ & $1: 3$ & 100 & 60 & 85 \\
\hline 32 & DMAc & 0.082 & $\mathrm{Cs}_{2} \mathrm{CO}_{3} / 1.5$ & $1: 3$ & 60 & 120 & 90 \\
\hline 33 & DMAc & 0.082 & $\mathrm{Cs}_{2} \mathrm{CO}_{3} / 1.5$ & $1: 3$ & 80 & 90 & 95 \\
\hline 34 & DMAc & 0.082 & $\mathrm{Cs}_{2} \mathrm{CO}_{3} / 1.5$ & $1: 3$ & 120 & 30 & 99 \\
\hline
\end{tabular}

Reaction conditions: iodobenzene $(1.0 \mathrm{mmol})$, methyl acrylate, catalyst, solvent $(1 \mathrm{ml})$

${ }^{a}$ Hexamethylenediamine

${ }^{\mathrm{b}} 1: 1$

${ }^{\mathrm{c}} \mathrm{GC}$ yield

Attempts to diminish the amount of the base (Entry 30-31) below the stoichiometric amounts gave lower yields, which can be explained by the involvement of the base in a catalytic cycle-stripping iodine from the saturated 
Table 3 Comparison of the prepared catalyst with other catalysts for Heck crosscoupling reactions from iodobenzene with methyl acrylate

\begin{tabular}{llllll}
\hline Entry & Catalyst & Time $(\mathrm{h})$ & $\begin{array}{l}\text { Tempera- } \\
\text { ture }\left({ }^{\circ} \mathrm{C}\right)\end{array}$ & Yield $(\%)$ & TOF $\left(\mathrm{h}^{-1}\right)^{\mathrm{c}}$ \\
\hline 1 & $\mathrm{Pd}(\mathrm{OAc})_{2} @ \mathrm{MNP}[14]$ & 1 & 100 & 97 & 194 \\
2 & $\mathrm{Pd} / \mathrm{SiO}_{2}[53]$ & 0.5 & 140 & 100 & 709 \\
3 & $\mathrm{Pd}-\mathrm{DABCO}-\boldsymbol{\gamma}-\mathrm{Fe}_{2} \mathrm{O}_{3}[58]$ & 0.5 & 100 & 90 & 180 \\
4 & $\mathrm{Palladacycle}[56]$ & 0.33 & 80 & 100 & 600 \\
5 & $\mathrm{Pd}(\mathrm{OAc})_{2}$ (ligand free) [57] & 1.5 & 80 & 91 & 61 \\
6 & $\mathrm{Pd}\left(\right.$ nano)/MNP@ IL-SiO ${ }_{2}[59]$ & 24 & 110 & 99 & 12 \\
7 & $\mathrm{Fe}_{3} \mathrm{O}_{4}-\mathrm{NH}_{2} @ \mathrm{MIL}-101-\mathrm{NH}_{2}-\mathrm{Pd}(\mathrm{OAc})_{2}{ }^{\mathrm{a}}$ & 0.66 & 100 & 92 & 1700 \\
8 & $\mathrm{Fe}_{3} \mathrm{O}_{4}-\mathrm{NH}_{2} @ \mathrm{MIL}-101-\mathrm{NH}_{2}-\mathrm{Pd}(\mathrm{OAc})_{2}{ }^{\mathrm{b}}$ & 0.5 & 120 & 99 & 2438 \\
\hline
\end{tabular}

${ }^{\text {a Entry }} 27$

${ }^{\mathrm{b}}$ Entry 34

${ }^{\mathrm{c}}$ TOF Turnover frequency calculated as mmol of obtained product per mmol of used Pd per unit of time $\left(\mathrm{h}^{-1}\right)$ palladium species and enabling it thus to enter a new reaction cycle (1-3). Although during the Heck reaction the base is theoretically consumed in 1:1 molar ratio to ArX, a slight excess is clearly beneficial (Entry 29). In the case when 0.5 equivalent of the base was used just $70 \%$ conversion was achieved after $1 \mathrm{~h}$ (Entry 30). These results can be hypothetically explained by the involvement of the solvent possessing the basic character and partial catalyst deactivation because of a lack of a sufficient amount of the base.

Experiments at different reaction temperatures (Entries 29, 32-34) allowed a preliminary estimation of the apparent activation energy, which was calculated to be $28.8 \mathrm{~kJ} / \mathrm{mol}$. A temperature increase can result in faster re-deposition of $\mathrm{Pd}$ on the support [53], influencing, however, metal agglomeration and thus leading to deactivation.

The scope of this work was limited to the reaction of iodobenzene and methyl acrylate. These compounds, in general, are considered the most reactive in the Heck reaction making them the most convenient for testing new materials, such as the catalyst developed in the current work. In generally, less reactive compounds would require prolonged reaction times or elevated temperatures [14, 56-58].

In Table 3, the catalytic activity of $\mathrm{Fe}_{3} \mathrm{O}_{4}-\mathrm{NH}_{2} @$ MIL$101-\mathrm{NH}_{2}-\mathrm{Pd}(\mathrm{OAc})_{2}$ in Heck cross-coupling reaction of iodobenzene with methyl acrylate is compared with a range of catalysts reported in the literature. To have a more fair comparison entry 27 was selected, when complete conversion was not achieved. Entry 34 illustrates the largest TOF achieved in the present study. As can be seen, $\mathrm{Fe}_{3} \mathrm{O}_{4}-\mathrm{NH}_{2} @$ MIL-101- $\mathrm{NH}_{2}-\mathrm{Pd}(\mathrm{OAc})_{2}$ is more effective than the catalysts reported previously. In addition, magnetic separation is another advantage of the catalyst developed in the current work.
Fig. 9 Recyclability study. Reaction conditions: DMAc $(1.0 \mathrm{ml})$, iodobenzene $(1.0 \mathrm{mmol})$, methyl acrylate $(3.0 \mathrm{mmol}), \mathrm{Cs}_{2} \mathrm{CO}_{3}$ ( $1.5 \mathrm{mmol})$, catalyst $0.05 \mathrm{~g}$ (0.082 mol \% Pd), temperature $120^{\circ} \mathrm{C}$, reaction time $30 \mathrm{~min}$

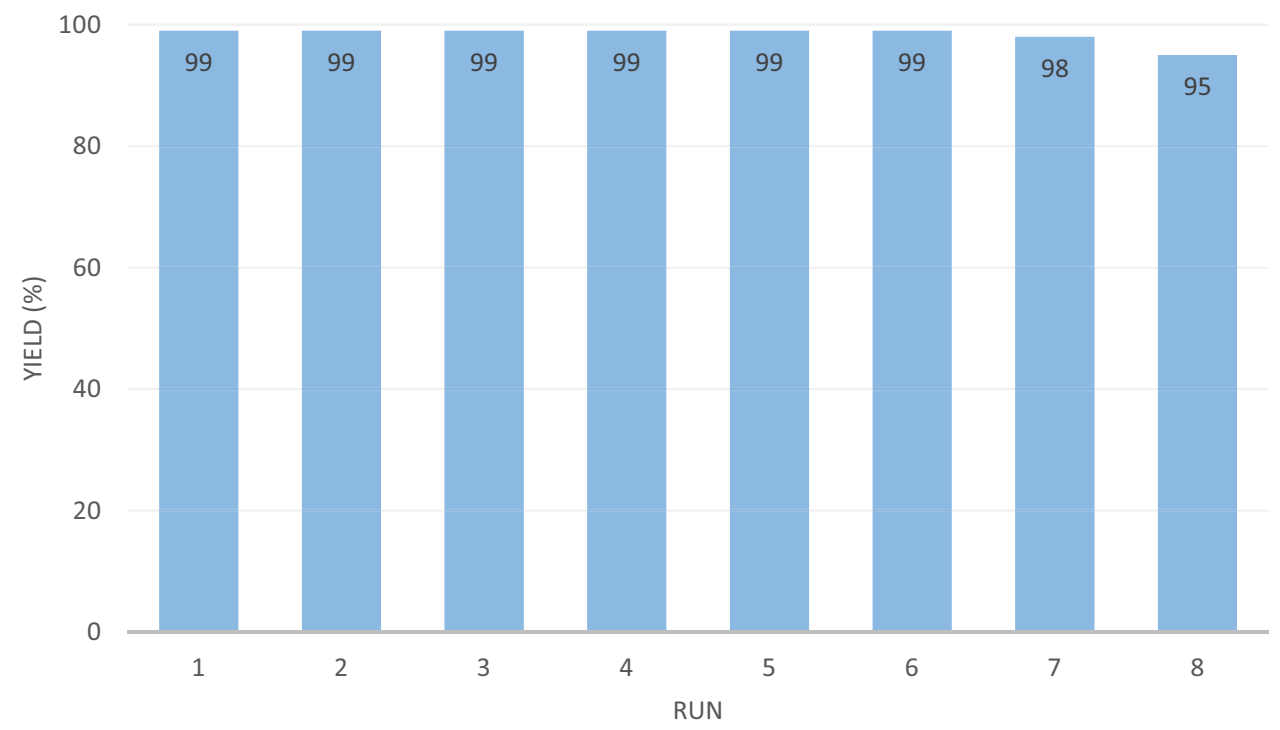


Finally, stability and reusability of supported Pd magnetic MOF was elucidated in the Heck cross-coupling reaction of iodobenzene and methyl acrylate as a model substrate under the optimized conditions. In order to reuse the catalyst, the magnetic nanocomposites were efficiently recovered by simple magnetic decantation after each cycle, washed with diethyl ether and ethyl acetate followed by adding a new batch of the reaction mixture. The supported magnetic MIL-101 catalyst can be reused at least seven times without significant losses of catalytic activity, (Fig. 9). Deactivation occurs probably due to slow Pd leaching, apparently requiring a separate investigation.

\section{Conclusions}

A reusable and efficient Pd supported on the magnetic MIL$101-\mathrm{NH}_{2}$ catalysts was synthesized and characterized by FT-IR, XPS, SEM, nitrogen physisorption, TGA, EDX, ICP, TEM, XRD and VSM. Activity of the catalyst was monitored through the model Heck cross-coupling reaction of iodobenzene and methyl acrylate for which conditions were thoroughly optimized. High activity was accomplished with good reusability. The catalyst could be easily separated from the reaction mixture with an external magnet and recycled for at least seven times.

The hybrid catalyst developed in this work combines properties of two emerging types of materials, magnetic nanoparticles and metal organic frameworks. It efficiently utilizes their advantages and can be further expanded for other catalytic reactions.

Acknowledgements Open access funding provided by Abo Akademi University (ABO).

\section{Compliance with Ethical Standards}

Conflict of interest The authors declare no conflict of interest.

Open Access This article is licensed under a Creative Commons Attribution 4.0 International License, which permits use, sharing, adaptation, distribution and reproduction in any medium or format, as long as you give appropriate credit to the original author(s) and the source, provide a link to the Creative Commons licence, and indicate if changes were made. The images or other third party material in this article are included in the article's Creative Commons licence, unless indicated otherwise in a credit line to the material. If material is not included in the article's Creative Commons licence and your intended use is not permitted by statutory regulation or exceeds the permitted use, you will need to obtain permission directly from the copyright holder. To view a copy of this licence, visit http://creativecommons.org/licenses/by/4.0/.

\section{References}

1. Heck RF, Nolley JP Jr (1972) Palladium-catalyzed vinylic hydrogen substitution reactions with aryl, benzyl, and styryl halides. J Org Chem 37:2320-2322

2. Heck RF (1979) Palladium catalyzed reactions of organic halides with olefins. Acc Chem Res 12:146-151

3. Mizoroki T, Mori K, Ozaki A (1971) Arylation of olefin with aryl iodide catalyzed by palladium. Bull Chem Soc Japan 44:581

4. Koy M, Sandfort F, Tlahuext-Aca A, Quach L, Daniliuc CG, Glorius F (2018) Palladium-catalyzed decarboxylative Heck-type coupling of activated aliphatic carboxylic acids enabled by visible light. Chemistry 24:4552-4555

5. Wang C, Xiao G, Guo T, Ding Y, Wu X, Loh TP (2018) Palladium-catalyzed regiocontrollable reductive heck reaction of unactivated aliphatic alkenes. J Am Chem Soc 140:9332-9336

6. Liwosz TW, Chemler SR (2012) Copper-catalyzed enantioselective intramolecular alkene amination/intermolecular heck-type coupling cascade. J Am Chem Soc 134:2020-2023

7. Yu J, Hong Z, Yang X, Jiang Y, Jiang Z, Su W (2018) Bromideassisted chemoselective Heck reaction of 3-bromoindazoles under high-speed ball-milling conditions: synthesis of axitinib. Beilstein J Org Chem 14:786-795

8. Motevalizadeh SF, Alipour M, Ashori F, Samzadeh-Kermani A, Hamadi H, Ganjali MR, Aghahosseini H, Ramazani A, Khoobi M, Gholibegloo E (2018) Heck and oxidative boron Heck reactions employing Pd(II) supported amphiphilized polyethyleneiminefunctionalized MCM-41 (MCM-41@aPEI-Pd) as an efficient and recyclable nanocatalyst. Appl Organomet Chem 32:e4123

9. Li Y, Wang K, Ping Y, Wang Y, Kong W (2018) Nickel-catalyzed domino Heck cyclization/Suzuki coupling for the synthesis of 3,3-disubstituted oxindoles. Org Lett 20:921-924

10. Jaska CA, Manners I (2004) Heterogeneous or homogeneous catalysis? Mechanistic studies of the rhodium-catalyzed dehydrocoupling of amine-borane and phosphine-borane adducts. J Am Chem Soc 126:9776-9785

11. Ananikov VP, Orlov NV, Beletskaya IP (2007) Highly efficient nickel-based heterogeneous catalytic system with nanosized structural organization for selective Se-H bond addition to terminal and internal alkynes. Organometallics 26:740-750

12. Huang Y, Ma T, Huang P, Wu D, Lin Z, Cao R (2013) Direct C-H bond arylation of indoles with aryl boronic acids catalyzed by palladium nanoparticles encapsulated in mesoporous metal-organic framework. ChemCatChem 5:1877-1883

13. Mannathan S, Raoufmoghaddam S, Reek JNH, de Vries JG, Minnaard AJ (2017) Enantioselective intramolecular reductive Heck reaction with a palladium/monodentate phosphoramidite catalyst. ChemCatChem 9:551-554

14. Zhang Q, Zhao X, Wei HX, Li JH, Luo J (2017) Silica-coated nano- $\mathrm{Fe}_{3} \mathrm{O}_{4}$-supported iminopyridine palladium complex as an active, phosphine-free and magnetically separable catalyst for Heck reactions. Appl Organomet Chem 31:e3608

15. Khajehzadeh M, Moghadam M (2018) A new poly(N-heterocyclic carbene Pd complex) immobilized on nano silica: an efficient and reusable catalyst for Suzuki-Miyaura, Sonogashira and HeckMizoroki C-C coupling reactions. J Organomet Chem 863:60-69

16. Zhou HC, Long JR, Yaghi OM (2012) Introduction to metalorganic frameworks. Chem Rev 12:673-674

17. Xu F, Kang WF, Wang XN, Kou HD, Jin Z, Liu CS (2017) Synergic effect of copper-based metal-organic frameworks for highly efficient C-H activation of amidines. RSC Adv 7:51658-51662

18. Wang XS, Huang YB, Lin ZJ, Cao R (2014) Phosphotungstic acid encapsulated in the mesocages of amine-functionalized 
metal-organic frameworks for catalytic oxidative desulfurization. Dalt Trans 43:11950-11958

19. Chen L, Rangan S, Li J, Jiang H, Li Y (2014) A molecular Pd(ii) complex incorporated into a MOF as a highly active single-site heterogeneous catalyst for $\mathrm{C}-\mathrm{Cl}$ bond activation. Green Chem 16:3978-3985

20. Yang Q, Chen YZ, Wang ZU, Xu Q, Jiang HL (2015) One-pot tandem catalysis over Pd@MIL-101: boosting the efficiency of nitro compound hydrogenation by coupling with ammonia borane dehydrogenation. Chem Commun 51:10419-10422

21. Li X, Zhang B, Van Zeeland R, Tang L, Pei Y, Qi Z, Goh TW, Stanley LM, Huang W (2018) Unveiling the effects of linker substitution in Suzuki coupling with palladium nanoparticles in metal-organic frameworks. Catal Lett 148:940-945

22. Huang Y, Liu S, Lin Z, Li W, Li X, Cao R (2012) Facile synthesis of palladium nanoparticles encapsulated in amine-functionalized mesoporous metal-organic frameworks and catalytic for dehalogenation of aryl chlorides. J Catal 292:111-117

23. Pascanu V, Yao Q, Bermejo Gõmez A, Gustafsson M, Yun Y, Wan W, Samain L, Zou X, Martin-Mature B (2013) Sustainable catalysis: Rational Pd loading on MIL-101Cr-NH2 for more efficient and recyclable Suzuki-Miyaura reactions. Chemistry 19:17483-17493

24. Kang T, Li F, Baik S, Shao W, Ling D, Hyeon T (2017) Surface design of magnetic nanoparticles for stimuli-responsive cancer imaging and therapy. Biomaterials 136:98-114

25. Zamora-Mora V, Fernández-Gutiérrez M, González-Gómez Á, Sanz B, Román JS, Goya GF et al (2017) Chitosan nanoparticles for combined drug delivery and magnetic hyperthermia: From preparation to in vitro studies. Carbohydr Polym 157:361-370

26. González-Sálamo J, Socas-Rodríguez B, Hernández-Borges J, Rodríguez-Delgado MÁ (2017) Core-shell poly(dopamine) magnetic nanoparticles for the extraction of estrogenic mycotoxins from milk and yogurt prior to LC-MS analysis. Food Chem 215:362-368

27. Rostamnia S, Nuri A, Xin H, Pourjavadi A, Hosseini SH (2013) Water dispersed magnetic nanoparticles $\left(\mathrm{H}_{2} \mathrm{O}-\mathrm{DMNPs}\right)$ of $\gamma-\mathrm{Fe}_{2} \mathrm{O}_{3}$ for multicomponent coupling reactions: a green, single-pot technique for the synthesis of tetrahydro-4H-chromenes and hexahydroquinoline carboxylates. Tetrahedron Lett 54:3344-3347

28. Gholinejad M, Zareh F, Nájera C (2018) Nitro group reduction and Suzuki reaction catalysed by palladium supported on magnetic nanoparticles modified with carbon quantum dots generated from glycerol and urea. Appl Organomet Chem 32:e3984

29. Sharma H, Mahajan $\mathrm{H}$, Jamwal B, Paul S (2018) $\mathrm{Cu} @ \mathrm{Fe}_{3} \mathrm{O}_{4}-\mathrm{TiO}_{2^{-}}$ L-Dopa: A novel and magnetic catalyst for the Chan-Lam cross-coupling reaction in ligand free conditions. Catal Commun 107:68-73

30. Zhang HY, Hao XP, Mo LP, Liu SS, Zhang WB, Zhang ZH (2017) A magnetic metal-organic framework as a highly active heterogeneous catalyst for one-pot synthesis of 2-substituted alkyl and aryl(indolyl)kojic acid derivatives. New J Chem 41:7108-7115

31. Huo SH, Yan XP (2012) Facile magnetization of metal-organic framework MIL-101 for magnetic solid-phase extraction of polycyclic aromatic hydrocarbons in environmental water samples. Analyst 137:3445-3451

32. Qian Tang X, Dan Zhang Y, Wei Jiang Z, Mei Wang D, Zhi Huang C, Fang LY (2018) $\mathrm{Fe}_{3} \mathrm{O}_{4}$ and metal-organic framework MIL$101(\mathrm{Fe})$ composites catalyze luminol chemiluminescence for sensitively sensing hydrogen peroxide and glucose. Talanta 179:43-50

33. Huang YF, Liu M, Wang YQ, Li Y, Zhang JM, Huo SH (2016) Hydrothermal synthesis of functionalized magnetic MIL-101 for magnetic enrichment of estrogens in environmental water samples. RSC Adv 6:15362-15369

34. Rahmaninia A, Mansoori Y, Nasiri F (2018) Surface-initiated atom transfer radical polymerization of a new rhodanine-based monomer for rapid magnetic removal of $\mathrm{Co}$ (II) ions from aqueous solutions. Polym Adv Technol 29:1988-2001
35. Rahman N, Haseen U (2015) Development of polyacrylamide chromium oxide as a new sorbent for solid phase extraction of As(III) from food and environmental water samples. RSC Adv 5:7311-7323

36. Serra-Crespo P, Ramos-Fernandez EV, Gascon J, Kapteijn F (2011) Synthesis and characterization of an amino functionalized MIL-101(Al): Separation and catalytic properties. Chem Mater 23:2565-2572

37. Wang S, Bromberg L, Schreuder-Gibson H, Hatton TA (2013) Organophophorous ester degradation by chromium(III) terephthalate metal-organic framework (MIL-101) chelated to N, N-dimethylaminopyridine and related aminopyridines. ACS Appl Mater Interfaces 5:1269-1278

38. Choi KM, Na K, Somorjai GA, Yaghi OM (2015) Chemical environment control and enhanced catalytic performance of platinum nanoparticles embedded in nanocrystalline metal-organic frameworks. J Am Chem Soc 137:7810-7816

39. Hermannsdörfer J, Kempe R (2011) Selective palladium-loaded MIL-101 catalysts. Chemistry 17:8071-8077

40. Liu J, Sun Z, Deng Y, Zou Y, Li C, Guo X, Xiong L, Gao Y, Li F, Zhao D (2009) Highly water-dispersible biocompatible magnetite particles with low cytotoxicity stabilized by citrate groups. Angew Chem Int Ed 48:5875-5879

41. Bernt S, Guillerm V, Serre C, Stock N (2011) Direct covalent postsynthetic chemical modification of Cr-MIL-101 using nitrating acid. Chem Commun 47:2838-2840

42. Zhao H, Li L, Wang J, Wang R (2015) Spherical core-shell magnetic particles constructed by main-chain palladium $\mathrm{N}$-heterocyclic carbenes. Nanoscale 7:3532-3538

43. Lehmann F (2004) Cesium carbonate $\left(\mathrm{Cs}_{2} \mathrm{CO}_{3}\right)$. Synlett 13:2447-2448

44. Lautens M, Piguel S (2000) A new route to fused aromatic compounds by using a palladium-catalyzed alkylation-alkenylation sequence. Angew Chemie 112:1087-1088

45. Littke AF, Fu GC (1999) Heck reactions in the presence of $\mathrm{P}(\mathrm{t}-\mathrm{Bu}) 3$ : expanded scope and milder reaction conditions for the coupling of aryl chlorides. J Org Chem 64:10-11

46. Grasa GA, Singh R, Stevens ED, Nolan SP (2003) Catalytic activity of $\mathrm{Pd}(\mathrm{II})$ and $\mathrm{Pd}(\mathrm{II}) / \mathrm{DAB}-\mathrm{R}$ systems for the Heck arylation of olefins. J Organomet Chem 687:269-279

47. Littke AF, Fu GC (1998) A convenient and general method for Pdcatalyzed Suzuki cross-couplings of aryl chlorides and arylboronic acids. Angew Chemie Int Ed 37:3387-3388

48. Eckhardt M, Fu GC (2003) The first applications of carbene ligands in cross-couplings of alkyl electrophiles: sonogashira reactions of unactivated alkyl bromides and iodides. J Am Chem Soc 125:13642-13643

49. Batey RA, Shen M, Lough AJ (2002) Carbamoyl-substituted $\mathrm{N}$-heterocyclic carbene complexes of palladium(II): application to Sonogashira cross-coupling reactions. Org Lett 4:1411-1414

50. Yang C, Nolan SP (2001) A highly efficient palladium/imidazolium salt system for catalytic Heck reactions. Synlett 10:1539-1542

51. Aksin Ö, Türkmen H, Artok L, Çetinkaya B, Ni C, Büyükgüngör O, Özkal E (2006) Effect of immobilization on catalytic characteristics of saturated Pd-N-heterocyclic carbenes in Mizoroki-Heck reactions. J Organomet Chem 691:3027-3036

52. de Vries AHM, Mulders JMCA, Mommers JHM, Henderickx HJW, de Vries JG (2003) Homeopathic ligand-free palladium as a catalyst in the Heck reaction. A comparison with a palladacycle. Org Lett 5:3285-3288

53. Zhao F, Bhanage BM, Shirai M, Arai M (2000) Heck reactions of iodobenzene and methyl acrylate with conventional supported palladium catalysts in the presence of organic and/or inorganic bases without ligands. Chemistry 6:843-848

54. Ji Y, Jain S, Davis RJ (2005) Investigation of Pd leaching from supported Pd catalysts during the Heck reaction. J Phys Chem B 109:17232-17238 
55. Kŏhler K, Kleist W, Přck SS (2007) Genesis of coordinatively unsaturated palladium complexes dissolved from solid precursors during Heck coupling reactions and their role as catalytically active species. Inorg Chem 46:1876-1883

56. Rosol M, Moyano A (2005) 1'-Carbopalladated-4-ferrocenyl-1,3-oxazolines as catalysts for Heck reactions: further evidence in support of the $\mathrm{Pd}(0) / \mathrm{Pd}(\mathrm{II})$ mechanism. J Organomet Chem 690:2291-2296

57. Han W, Liu N, Liu C, Jin ZL (2010) A ligand-free Heck reaction catalyzed by the in situ-generated palladium nanoparticles in PEG400. Chin Chem Lett 12:1411-1414

58. Sobhani S, Pakdin-Parizi Z (2014) Palladium-DABCO complex supported on $\gamma-\mathrm{Fe}_{2} \mathrm{O}_{3}$ magnetic nanoparticles: a new catalyst for $\mathrm{C}=\mathrm{C}$ bond formation via Mizoroki-Heck cross-coupling reaction. Appl Catal A Gen 479:112-120

59. Omar S, Abu-Reziq R (2014) Palladium nanoparticles supported on magnetic organic-silica hybrid nanoparticles. J Phys Chem C 118:30045-30056

Publisher's Note Springer Nature remains neutral with regard to jurisdictional claims in published maps and institutional affiliations.

\section{Affiliations}

\section{Ayat Nuri ${ }^{1,2} \cdot$ Nemanja Vucetic $^{2} \cdot$ Jan-Henrik Smått ${ }^{3} \cdot$ Yaghoub Mansoori $^{1} \cdot$ Jyri-Pekka Mikkola $^{2,4} \cdot$ Dmitry Yu. Murzin $^{2}$}

\section{Dmitry Yu. Murzin}

dmurzin@abo.fi

1 Department of Applied Chemistry, Faculty of Science, University of Mohaghegh Ardabili, Ardabil, Iran

2 Laboratory of Industrial Chemistry and Reaction Engineering, Johan Gadolin Process Chemistry Centre, Åbo Akademi University, Biskopsgatan 8, 20500 Turku, Finland
3 Laboratory of Molecular Science and Engineering, Åbo Akademi University, Porthansgatan 3-5, 20500 Turku, Finland

4 Technical Chemistry, Department of Chemistry, Chemical-Biological Center, Umeå University, 90187 Umeå, Sweden 